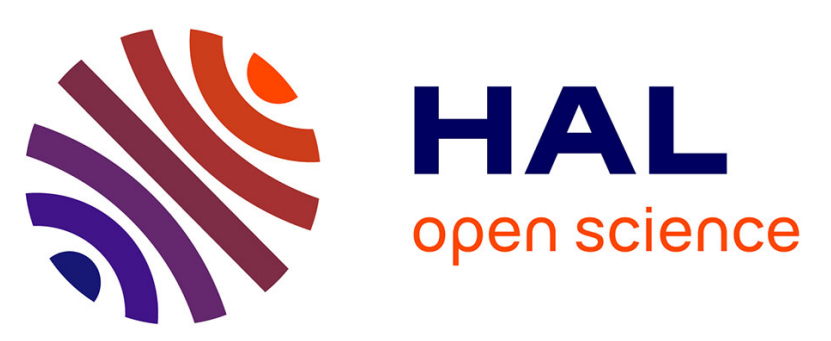

\title{
Influence of field retting duration on the biochemical, microstructural, thermal and mechanical properties of hemp fibres harvested at the beginning of flowering
} Brahim Mazian, Anne Bergeret, Jean-Charles Bénézet, Luc Malhautier

\section{- To cite this version:}

Brahim Mazian, Anne Bergeret, Jean-Charles Bénézet, Luc Malhautier. Influence of field retting duration on the biochemical, microstructural, thermal and mechanical properties of hemp fibres harvested at the beginning of flowering. Industrial Crops and Products, 2018, 116, pp.170-181. 10.1016/j.indcrop.2018.02.062 . hal-01799342

\section{HAL Id: hal-01799342 \\ https://hal.science/hal-01799342}

Submitted on 27 Apr 2020

HAL is a multi-disciplinary open access archive for the deposit and dissemination of scientific research documents, whether they are published or not. The documents may come from teaching and research institutions in France or abroad, or from public or private research centers.
L'archive ouverte pluridisciplinaire HAL, est destinée au dépôt et à la diffusion de documents scientifiques de niveau recherche, publiés ou non, émanant des établissements d'enseignement et de recherche français ou étrangers, des laboratoires publics ou privés. 


\title{
Influence of field retting duration on the biochemical, microstructural, thermal and mechanical properties of hemp fibres harvested at the beginning of flowering
}

\author{
Brahim Mazian $^{\mathrm{a}, \mathrm{b}}$, Anne Bergeret ${ }^{\mathrm{a}, *}$, Jean-Charles Benezet ${ }^{\mathrm{a}}$, Luc Malhautier ${ }^{\mathrm{b}}$

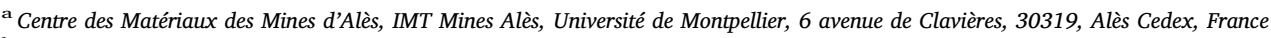 \\ ${ }^{\mathrm{b}}$ Laboratoire du Génie de l'Environnement Industriel, IMT Mines Alès, Université de Montpellier, 6 avenue de Clavières, 30319, Alès Cedex, France
}

\begin{abstract}
A B S T R A C T
The use of hemp fibres as reinforcements in polymer composites requires a thorough understanding of the hemp fibres transformation processes to obtain a constant quality. In this context, the upstream processing termed field retting is considered. Retting allows a subsequent fibre separation from the plant stems by degradation of cementing compounds by microorganisms. This operation depends on weather conditions and is currently empirically carried out in fields, so that a large variability in the hemp fibres quality (color, morphology, biochemical composition, thermal properties and mechanical properties) is resulting. Therefore, the present study aims to investigate the influence of different retting durations (up to 9 weeks) on hemp fibres properties when harvested at the beginning of flowering growth stage to survey their temporal dynamic. Various assessments were applied on fibres: color observations, morphological (optical microscope), surface (ESEM) and biochemical (gravimetry) analyses, spectrocolorimetric measurements (pectins content), thermogravimetric (TGA) analysis, and mechanical in tensile mode testings. The results reveal that increasing the field retting duration leads to a change of color characteristics from light green to grey due to the development of microbial communities (most probably fungal and bacteria) at the stem surface. A separation of the fibres bundle to elementary fibres occurs with the degradation of pectins during retting. An increase of thermal stability of the fibres is also observed. Both increase of cellulose fraction and crystallinity induce an enhancement in tensile properties.
\end{abstract}

Keywords:

Biochemical composition

Hemp fibre

Mechanical properties

Microstructure

Retting temporal dynamics

Thermal stability

\section{Introduction}

Hemp (Cannabis sativa L.) is an annual bast fibre plant from Asia and widely cultivated in many countries in Asia and Europe. Hemp bast fibres have traditionally been used for such purpose as the fabrication of textiles, and in recent years, are increasingly used as reinforcements in polymer composites due to their challenging performances including low-density (Aziz and Ansell, 2004), low cost (Dittenber and Gangarao, 2012), good specific mechanical properties (Bourmaud and Baley, 2010; Duval et al., 2011) and biodegradability (Stamboulis et al., 2001; Joshi et al., 2004) compared to conventional fibres such as glass fibres (Wambua et al., 2003). However, the huge variation of their biochemical, physical and mechanical properties (Duval et al., 2011; Placet et al., 2012) makes this natural fibre limited to use in structural application when high consistency and homogeneity are required (Stamboulis et al., 2001). The hemp fibres used for composites are primary and secondary fibres which are located between the epidermis and the xylem core and parallel to the longitudinal axis of the stem
(Schäfer and Honermeier, 2006). The hemp fibres are associated through their pectic middle lamella to form bundles of several dozens of fibres (Chabbert et al., 2005). For high performance composites, pectic middle lamella and other cementing compounds (e.g. wax) that bind the bast fibres and fibre bundles to other tissues must be removed in order to separate the fibres and to obtain individual fibres or smaller fibres bundles. This separation of the fibres bundles leads to improve interfacial bonding between fibres and matrix which enhances the mechanical performance of final composite (Li et al., 2009; Sisti et al., 2016). In the hemp industry, traditional extraction and separation processes are commonly used to facilitate the separation of the fibres from stem and reduce fibre defects during decortication. These processes play a key role on the quality heterogeneity of hemp fibres, especially field retting treatment which consists to spread out hemp stems on the ground for a duration ranging from a few days to several weeks. When the plant stems are laid in the field, the microorganisms (fungi and bacteria) attack the stems producing a range of polysaccharide-degrading enzymes, especially pectinolytic which remove

\footnotetext{
* Corresponding author.

E-mail address: Anne.Bergeret@mines-ales.fr (A. Bergeret).
} 
the components in the middle lamella region surrounding the fibres (Akin et al., 2007; Henriksson et al., 1997).

Field retting is empirically carried out because of its very environmental-dependent conditions (temperature, humidity and duration) which results many problems of the inconsistency of the hemp fibres quality. For this reason, many efforts are nowadays directed for offering alternative methods of extraction of the fibres such as thermal and enzymatic treatment (Nykter et al., 2008), steam explosion (Vignon et al., 1997) and chemical treatment (Obendorf and Kyung, 2006). These methods are well-controlled, but economic viability for industrial upscaling still remains difficult because they are expensive and need more energy or specific enzymes, contrary to the field retting that is cheaper and easier to be applied (Tahir et al., 2011). Therefore, field retting remains the most widely used in Europe for industrial production of bast fibres and thus must be understood in order to avoid the insufficient advancement of field retting which makes separation of the fibres difficult, or over retting that leads to a partial degradation of fibres by cellulose destructuring (Sharma and Brown, 1984).

Field retting is usually carried out at the maturity growth stage since the farmers could be retrieved the seed. However, this growth stage occurs in autumn when climatic conditions are not favorable for a better master of field retting progress. A recent study of Liu et al. (2015a) highlights that the field retting of the hemp fibres harvested at seed maturity during a colder and rainy season lead to a rapid change of the properties of the fibres. Indeed, the hemp fibres quality increases at the early stage (1 week) of the field retting and then rapidly decreases by extending the retting process, due to the accelerated degradation of cellulose by microorganisms. Placet et al. (2017) compared unretted and 5 weeks-retted fibres during a very rainy retting period, and found that the prolongation of retting under these climatic conditions has caused over-retted fibres. Therefore, full understanding of the evolution of the quality of hemp fibre during field retting process requires a study for a long period with a gradual development and activity of microorganisms. For this reason, the field retting of hemp fibres harvested at the beginning of flowering growth stage which coincides with summer conditions is investigated in this study.

The purpose of the present work was then to evaluate the effect of different field retting durations on the properties of the hemp fibres when harvested at the beginning of flowering growth stage i.e. to survey the temporal dynamic of hemp fibres composition, microstructure, thermal and mechanical properties during retting. The color change was analyzed by visual observations. The changing biochemical composition, pectin variation, crystalline structure was determined using successive solvent extractions, spectrocolorimetric and X-ray diffraction measurements, respectively. Thermal stability was studied by thermogravimetry analyses (TGA). Scanning electron and optical microscopy observations were carried out to examine the stem surface change and morphology of fibres. Finally, tensile tests were performed on manually extracted fibre bundles. In addition, this work will also contribute to the missing data on fibre harvested at beginning of flowering and retted for a long period under dry weather conditions.

\section{Materials and methods}

\subsection{Raw material}

\subsubsection{Cultivation}

The hemp (Cannabis sativa L., Cultivar Santhica 27) was grown at a rate of $30 \mathrm{~kg} / \mathrm{ha}$ on May 6th, 2016 in the south of France around the Mas La Valus (GPS: N44.130673, E4.315895 ${ }^{\circ}$ by CIVAM Chanvre Gardois association (Bouquet, France). The hemp plants were manually pulled using a shear at the beginning of flowering (July 25th, 2016) and dew-retted in the field. Following the definition of the different hemp growth stages described by Mediavilla et al. (1998), the beginning of flowering period selected is corresponding to code 2101 (first opened staminate flowers). Plants harvested were turned regularly (once a week) on the ground to homogenize the retting of the stems.
Table 1

Name of samples collected during different retting times.

\begin{tabular}{lllllllllll}
\hline Retting time (day) & 0 & 7 & 14 & 21 & 28 & 35 & 42 & 49 & 56 & 63 \\
\hline Samples name & R0 & R1 & R2 & R3 & R4 & R5 & - & - & - & R9 \\
\hline
\end{tabular}

\subsubsection{Sampling and weather conditions}

After harvesting period, a weekly manual collection of the samples during retting was carried out. Table 1 gives the retting times and corresponding collected samples, from unretted fibres (R0) to 9 weeksretted fibres (R9). Stems collected were dried and stored in a cold $\left(4^{\circ} \mathrm{C}\right)$ room before being further processed.

Temperature and relative humidity have been constantly recorded in the field using three hygro-bouton sensors (Progesplus, Carquefou, France) that were put in contact with the soil. Daily average rainfall was obtained from Meteo France (weather station located at Méjannesle-Clap (GPS: N44.221944, $\mathrm{E} 4.344722^{\circ}$ ) in the vicinity of the Mas de la Valus). Daily weather conditions are exposed on Fig. 1 . The weather was warm during retting period, except the last three weeks in September 2016. The maximum and minimum temperatures between the 1st week and the 6th week of retting period ranged from 38 to $55^{\circ} \mathrm{C}$ and $15-20^{\circ} \mathrm{C}$, respectively, whereas during the last two weeks of the retting period, it decreased to $27-34^{\circ} \mathrm{C}$ and $10{ }^{\circ} \mathrm{C}-20^{\circ} \mathrm{C}$, respectively. Rainfall and humidity were not homogeneously distributed during the retting period. There was little rainfall $(11 \mathrm{~mm})$ during the 1 st and 4 th weeks of retting period, while between the 7th week and the last sample collection, it was higher $(50 \mathrm{~mm})$. Rainfall generally increases the relative humidity from $55 \%$ to $90 \%$.

The average length of the stems harvested at the beginning of flowering is $1.7 \pm 0.1 \mathrm{~m}$. In this present study, only the middle part of the stems with a length of $1 \mathrm{~m}$ was considered (Fig. 2) in order to limit the scatter of the results. Indeed other authors Liu et al. (2015b) and Duval et al. (2011) revealed that the location of the fibres on the stems (bottom, middle and top) influences the quality of fibres and the fibres issued from the middle part of the stems provide higher mechanical properties.

\subsection{Experimental methods}

\subsubsection{Visual aspect}

The color evaluation of the middle-stems and fibres along retting process was visually observed. The fibres were extracted using a razor blade and flat files.

\subsubsection{Microscopy observations}

The middle part of unretted (R0) and retted stems (R3, R5 and R9) was observed through scanning electron microscopy (ESEM) using an environmental scanning electron microscope Quanta FEG 200 (FEI, Merignac, France) with a magnification of $\times 500$ and $\times 1000$.

The influence of field retting durations on the morphology of fibres was also investigated using optical microscopy (Leica Laborlux 11 POL S). Prior to optical microscopy observation, the cross sections of the unretted (R0) and retted stems (R3, R5 and R9) were cut manually, commonly coated in an epoxy resin, and then subsequently polished to obtain smooth samples. Images were recorded using Archimed software in order to analyze qualitatively the evolution of bast fibres during field retting.

\subsubsection{Biochemical analysis}

Two methods were used, one based on solvent extractions to quantify cellulose, lignin and lipophilic extractives contents, the other based on spectrophotometry to evaluate the pectin content.

2.2.3.1. Solvent extractions. The biochemical composition of the fibres from unretted (R0) and retted hemp fibres (R3, R5 and R9) was 


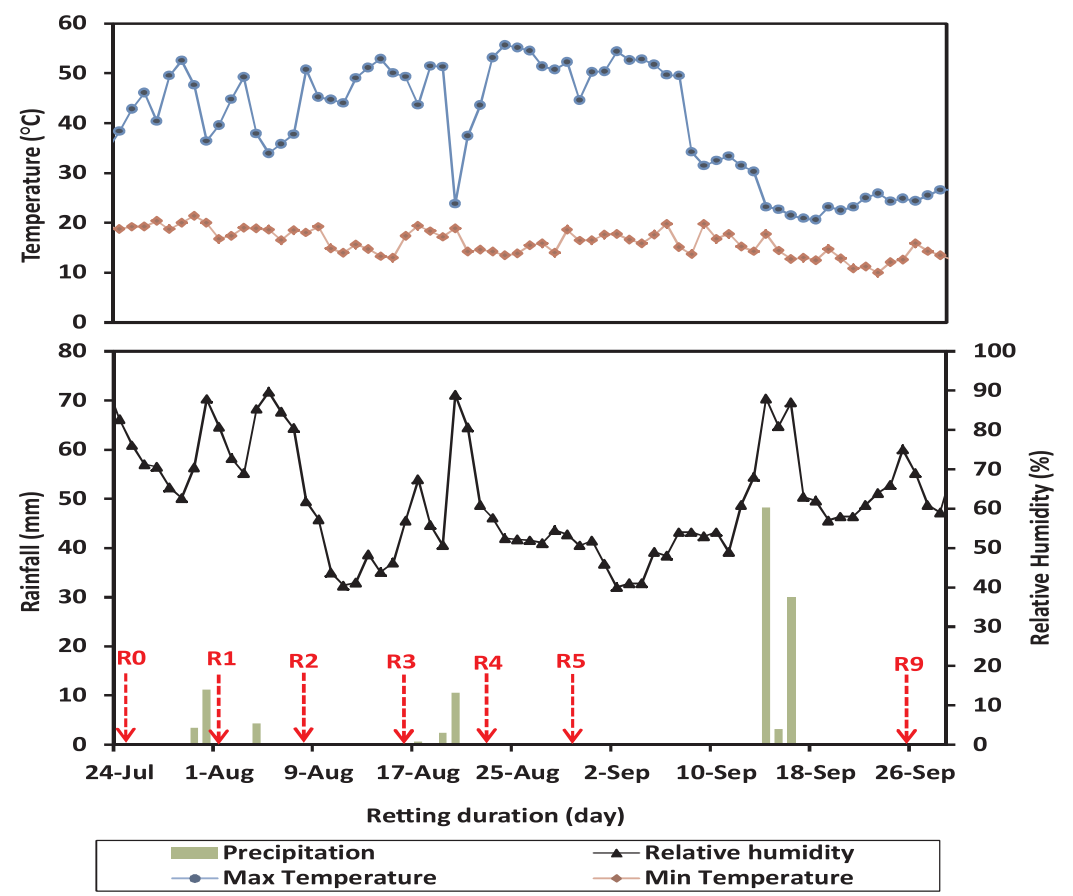

Fig. 1. Daily weather conditions (Minimum and maximum temperature, relative humidity and precipitation) during different retting durations in July to September 2016.

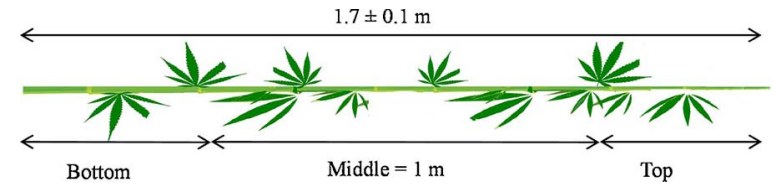

Fig. 2. Locations of the fibres on the stem (bottom, middle and top).

determined using successive solvent extractions based on different ASTM test methods as described on Fig. 3.

Prior to analyzing the chemical composition, fibres on stems were peeled and cut manually to obtain $10 \mathrm{~g}$ (weight of moisture free). Lipophilic extractives (waxes, fats, resins and some gums) were extracted with a solution of toluene/ethanol $(2: 1 \mathrm{w} / \mathrm{w})$ for $8 \mathrm{~h}$, the residue was filtered and dried in a desiccator at $105^{\circ} \mathrm{C}$ before being weighted using an infrared balance (Precisa XM66, Precisa, Dietikon, Switzerland) at $105^{\circ} \mathrm{C}$ according to ASTM D1107-56 method. A fraction of the fibres retrieved after this first extraction was treated with sulfuric acid in order to hydrolyze carbohydrates by leaving an insoluble residue which is determined as lignin according to ASTM D 1106-56 method. For this purpose, $1 \mathrm{~g}$ of fibres was mixed with $72 \%$ of sulfuric acid $\left(\mathrm{H}_{2} \mathrm{SO}_{4}\right)$ by shaking constantly for $2 \mathrm{~h}$ at room temperature. The mixture was then diluted by adding distilled water to obtain a $\mathrm{H}_{2} \mathrm{SO}_{4}$ solution with a $3 \%$ concentration and boil for $4 \mathrm{~h}$. The insoluble materials were filtered and dried at $105^{\circ} \mathrm{C}$. Another fraction of fibres retrieved after the first extraction was used for the determination of holocellulose and $\alpha$-cellulose contents according to ASTM D 1104-56 and
ASTM D 1103-60 methods, respectively. For this purpose, fibres were introduced in a solution made of $150 \mathrm{ml}$ of distilled water, $0.2 \mathrm{ml}$ of acetic acid and $1 \mathrm{~g}$ of sodium chlorite $\left(\mathrm{NaClO}_{2}\right)$. The mixture was heated at $75^{\circ} \mathrm{C}$ and stirred constantly for $5 \mathrm{~h}$, during which $0.2 \mathrm{ml}$ of acetic acid and $1 \mathrm{~g}$ of sodium chlorite were added each hour. After $5 \mathrm{~h}$, the mixture was placed in an ice-water bath until the temperature of the solution reached $10^{\circ} \mathrm{C}$. Distilled water was used to wash the residue until the color changed into yellow. The residue is the holocellulose fraction and was dried in an oven at $105^{\circ} \mathrm{C}$, then weighted using an infrared balance at $105^{\circ} \mathrm{C}$. Holocellulose was finally solubilized in sodium hydroxide solution $(\mathrm{NaOH})$ and acetic acid to obtain $\alpha$-cellulose. Ash content was determined after a dry oxidation of the fibres at $600{ }^{\circ} \mathrm{C}$ for $8 \mathrm{~h}$ according to ASTM D 1102-84 method.

2.2.3.2. Pectins analysis by spectrophotometer. Pectin content was determined using a colorimetric method developed by Blumenkrantz and Asboe-Hansen (1973). This method consists of hydrolyzing pectics substances to galacturonic acid which is the main compound within pectins followed by a coloring step with a m-hydroxydiphenyl reagent at room temperature (Fig. 4).

Firstly, a standard assay was carried out using different quantities of commercial pectin (Coprale, Ales, France) between 0 and $8 \mu \mathrm{g}$ (volume of $40 \mu \mathrm{l}) .200 \mu \mathrm{l}$ of concentrated sulfuric acid $\mathrm{H}_{2} \mathrm{SO}_{4}(96 \%)$ were added to each well of microtiter containing $40 \mu \mathrm{l}$ of pectin, and then the plate was incubated at $80^{\circ} \mathrm{C}$ for $1 \mathrm{~h}$. After cooling at room temperature, the absorbance of the background samples was measured with a spectrophotometer

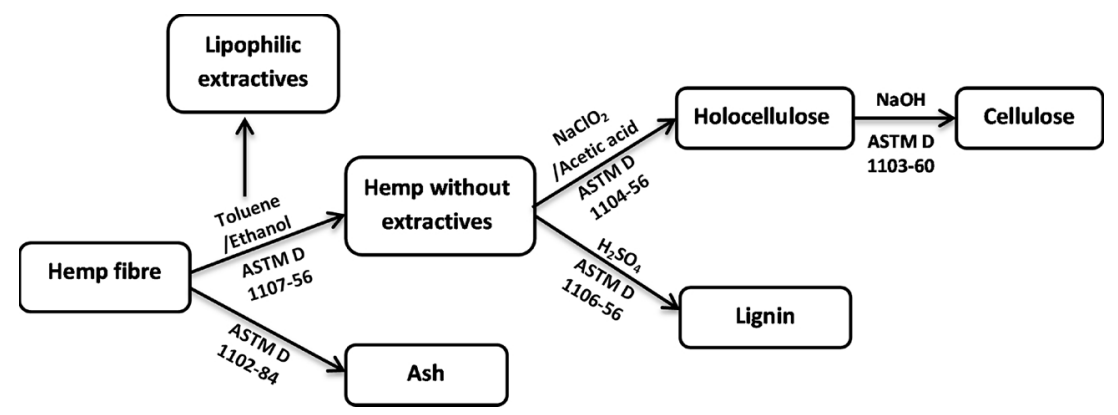

Fig. 3. Schema of successive solvent extractions used to analyze the biochemical composition of unretted and retted hemp fibres. 


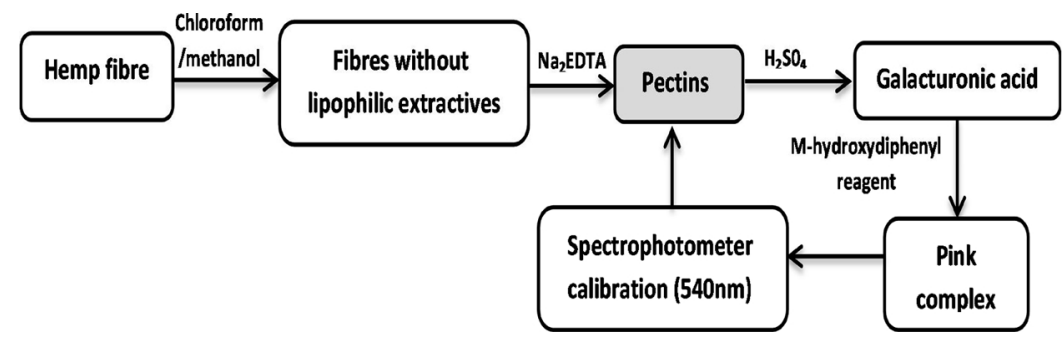

Fig. 4. Method used to analyze pectins content of unretted and retted fibres.

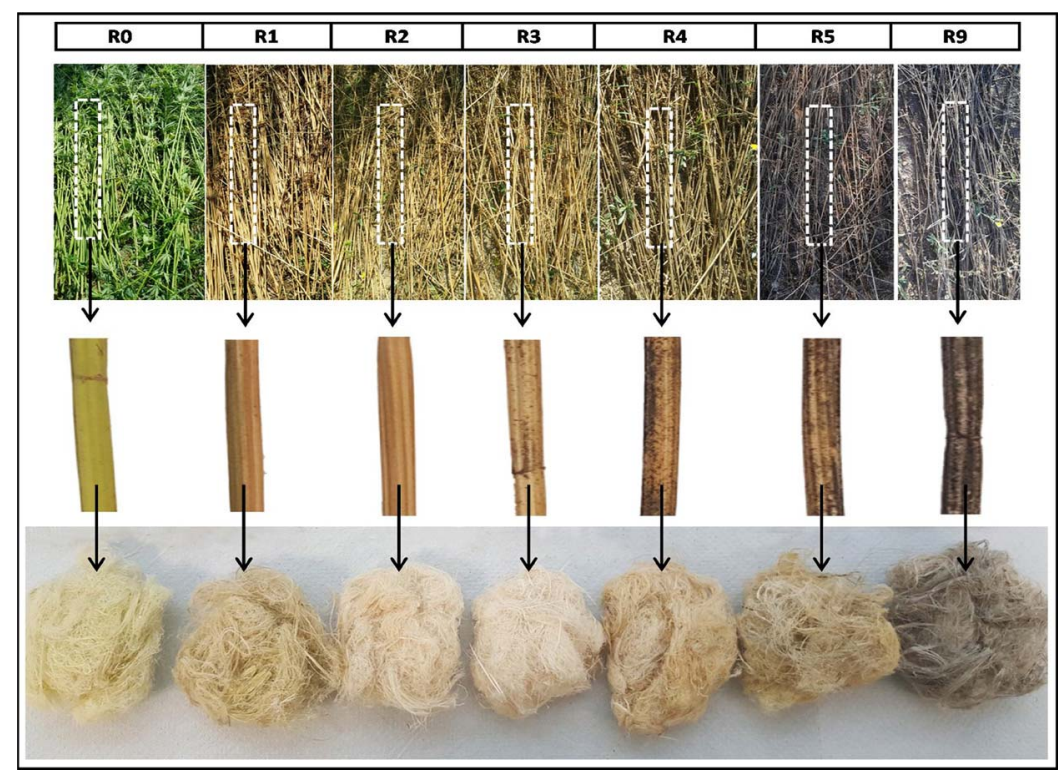

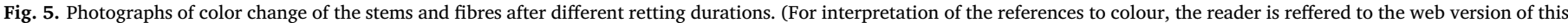
article.)

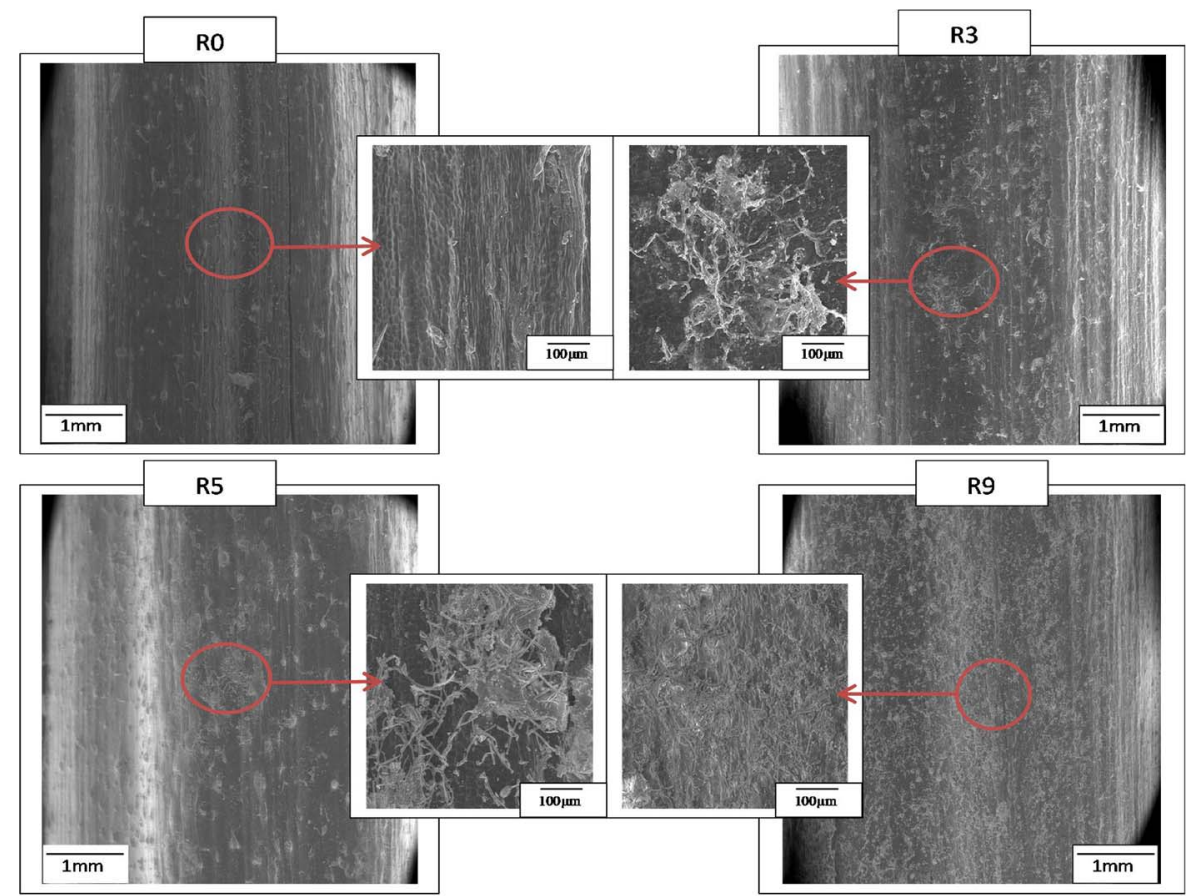

Fig. 6. ESEM images of unretted stem surface (R0), 3 weeks-retted stem surface (R3), 5 weeks retted stem surface (R5) and 9 weeks retted surface (R9). 


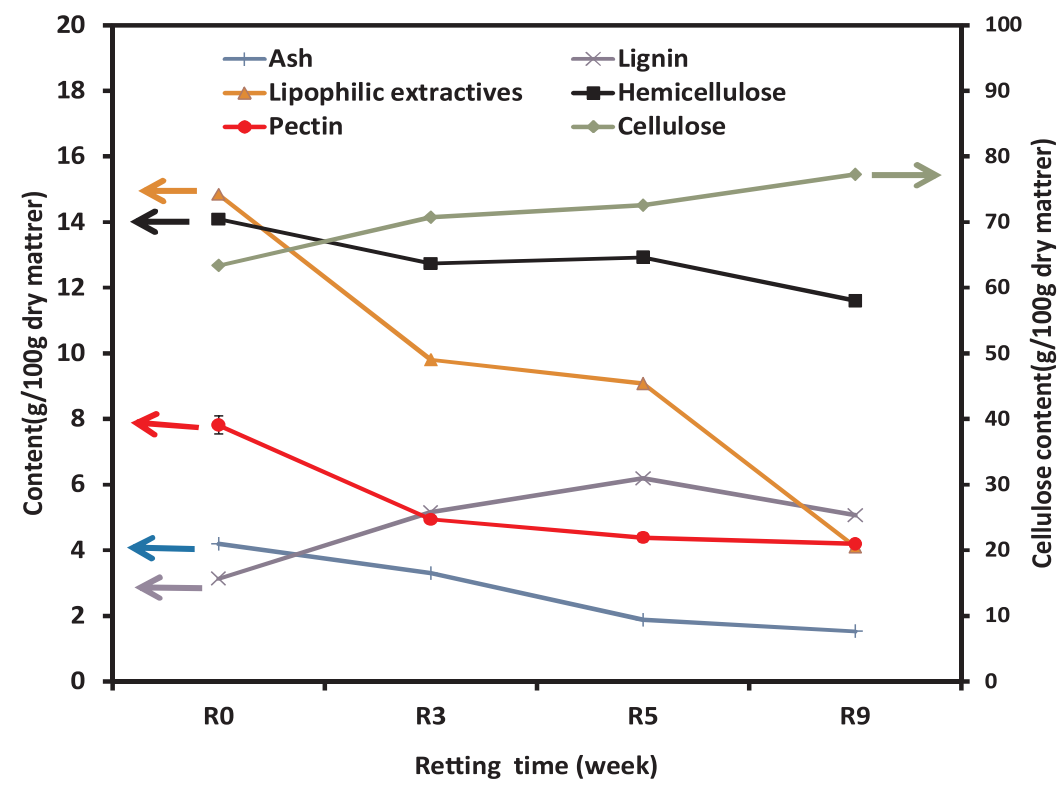

Fig. 7. Ash, lignin, hemicellulose, lipophilic extractives, hemicelluloses, cellulose (solvent extractions) and lignin (spectrophotometer) contents as a function of field retting times.

(Thermo scientific Multiskan spectrum, Waltham, MA USA) at $540 \mathrm{~nm}$. Then, $40 \mu \mathrm{l}$ of m-hydroxydiphenyl reagent $(100 \mu \mathrm{l}$ of $100 \mathrm{mg}$ of m-hydroxydiphenyl in $1 \mathrm{ml}$ of dimethylsulfoxide mixed with $4.9 \mathrm{ml}$ of $80 \%$ sulfuric acid) was added to each sample. A pink color appears and the highest absorbance of the samples is then measured at $540 \mathrm{~nm}$. The content of galacturonic acid is obtained after subtraction of the background absorbance. A calibration curve is obtained between $0-8 \mu$ g of galacturonic acid.

Subsequently, to determine the galacturonic acid amount of samples, an extraction of the pectins from fibres was performed as described by Fila et al. (2001). Fibres were peeled and cut manually on stems to obtain $200 \mathrm{mg}$ (weight of moisture free). Then lipid components were removed using a chloroform/methanol (1:1) solution by stirring constantly for $24 \mathrm{~h}$ at room temperature. After drying at $105^{\circ} \mathrm{C}$, pectins were then extracted with $200 \mathrm{ml}$ of $5 \mathrm{gl}^{-1} \mathrm{Na}_{2}$ EDTA for $2 \mathrm{~h}$ at $100^{\circ} \mathrm{C}$. The extraction product was then analyzed using the spectrophotometer calibration described above. The absorbance for unknown sample content is measured at $540 \mathrm{~nm}$, and the calibration curve is used to find the concentration of the galacturonic acid.

\subsubsection{X-Ray diffraction}

Microstructure of unretted (R0) and retted fibres (R3, R5 and R9) was analyzed using X-ray (XRD, AXS D8 Advance Bruker) diffractometer equipped with $\mathrm{Cu}-\mathrm{K} \alpha$ radiation $(\lambda=1.54 \AA)$. Measurements were performed on cut and compressed fibres (disks of $25 \mathrm{~mm}$ in diameter and $2 \mathrm{~mm}$ in thickness). X-ray diffractograms were recorded from 5 to $70^{\circ}$ ( $2 \theta$, degrees) with a scanning speed of $0.01 \%$. The crystalline order index (CI) was determined from X-ray diffractograms using a deconvolution method. Individual crystalline peaks were fitted using Origin ${ }^{\circledR}$ software assuming Gaussian functions. Iterations were repeated until the maximum $R^{2}$ value is superior than 0.98. (101), (101) and (002) crystalline peak areas (Ic) and amorphous broad peak area (Iam) were used to calculate the crystallinity order index according to Eq. (1).

$C I=\frac{I c}{I c+I a m} \times 100$

\subsubsection{Thermogravimetric analysis}

Thermogravimetric analyses of the unretted (R0) and retted hemp fibre (R3, R5 and R9) were carried out using a Perkin-Elmer Pyris-1 thermal analysis system. Samples of about $8 \mathrm{mg}$ manually extracted fibres (\$2.2.3.) were heated in nitrogen from $30{ }^{\circ} \mathrm{C}$ to $700{ }^{\circ} \mathrm{C}$ at the rate of $10^{\circ} \mathrm{C} / \mathrm{min}$. At least two samples from each retting time were performed. The mass change was recorded as a function of temperature. A differential thermogravimetric analysis (DTGA) curve was collected from the TGA analysis.

\subsubsection{Tensile test of fibre bundle}

Prior to tensile testing, the fibre bundles of the different retting durations (R0, R3, R5 and R9) were manually extracted from the stems after removing the epidermis using a razor blade. Fibre bundles were first positioned in one-part plastic tab with an UV-curing glue (DYMAX ultralight weld, DYMAX Europe GmbH, Wiesbaden, Germany). Then fibre bundles diameters are determined using an automated laser scanning device FDAS 765 (Diastron Ltd., Hampshire, UK). Fibres horizontally rotated within the laser beam at 21 slices along the fibre axis. The mean, the minimum and the maximum diameters for each slice are recorded in a dimensional report exported by UvWin 3.60 software. Thus, the mean diameters of 21 slices are averaged for each fibre bundle. The effective cross sectional area was calculated using the mean diameter of the fibre bundle assuming that the fibre had a circular shape. Fibre bundles were then mechanically tested under tensile mode at controlled temperature $\left(23^{\circ} \mathrm{C}\right)$ and relative humidity (48\%) using Diastron LEX810 system (Diastron Ltd., Hampshire, UK). The samples are loaded at a constant crosshead displacement speed of $1.2 \mathrm{~mm} / \mathrm{min}^{-1}$ and with $12 \mathrm{~mm}$ gauge length. A curve of force (Gram-Force) as function of displacement is obtained, and then the tensile strength, the Young's modulus and the failure strain were determined. Approximately 30 fibres were tested for each retting time (R0, R3, R5 and R9). The results were analyzed statistically using Analysis of variance ANOVA and Tukey multiple comparison test at significant level of $5 \%$.

\section{Results and discussion}

\subsection{Influence of field retting duration on the color of the hemp fibres}

A visual assessment of the samples collected after harvesting and during different retting times was carried out. Fig. 5 shows the photographs of the stems and of the processed fibres issued from different retting durations. A significant change of the color was observed. The color varies between light green for unretted samples (R0), yellow for low retted samples (R1 to R3), yellow with the presence of grey fibres for medium retted samples (R4 and R5) and grey for highly retted samples (R9). As it can be seen on the stems surface, grey spots start to 
A)

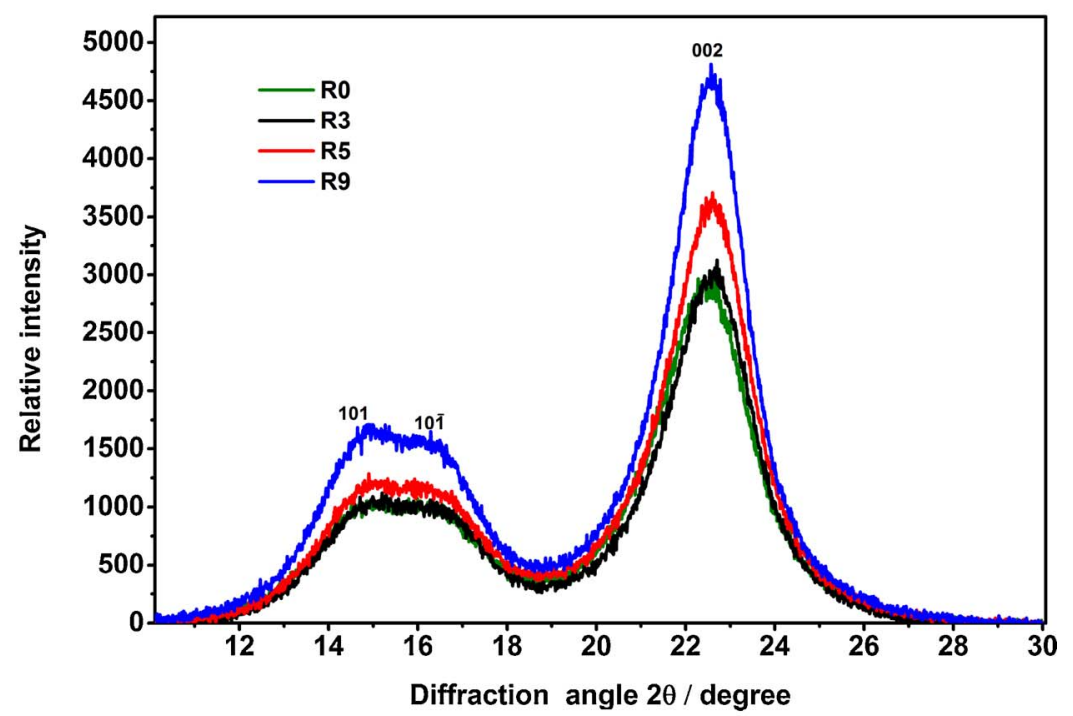

B)

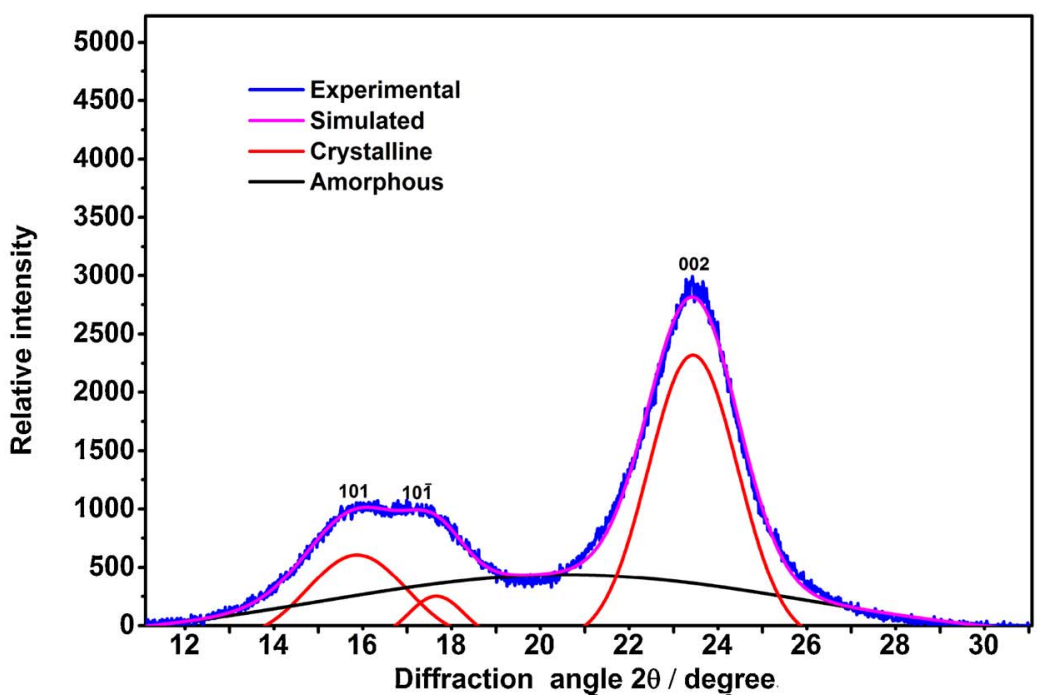

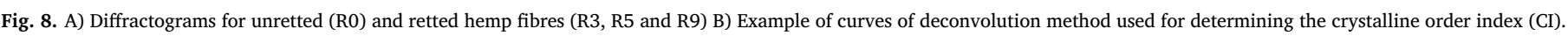
(For interpretation of the references to colour in this figure legend, the reader is referred to the web version of this article.)

Table 2

Crystallinity order index of unretted (R0) and retted hemp fibres (R3, R5 and R9).

\begin{tabular}{ll}
\hline Retting time & Crystallinity order index (\%) \\
\hline R0 & 53 \\
R3 & 58 \\
R5 & 68 \\
R9 & 73 \\
\hline
\end{tabular}

appear after 3 weeks and then invade the surface stems at 9th week of the field retting period. The fibres have the same color than the stems from which they have been extracted. A similar color change was previously reported by Martin et al. (2013) and Pallesen. (1996) after the field retting of flax fibres. ESEM images (Fig. 6) reveal that these grey spots are attributed to the development of microbial communities (fungal and bacteria (Ribeiro et al., 2015)) at the stem surface during field retting. The link between the increase of the grey and black color of the fibres during field retting and the activity of microorganisms especially fungi activity was also previously reported (Akin et al.,
2000). The microbial communities would start to colonize the stems surface after 3 weeks of retting (R3) and gradually cover the entire stems at the end of retting (R9). The large stem covering by microorganisms after 9 weeks of retting is probably due to more favorable conditions (higher rainfall $(50 \mathrm{~mm})$ after 7 th of field retting period) which enhanced the development of the microbial biofilm.

\subsection{Influence of field retting duration on the biochemical composition of hemp fibres}

The biochemical composition of the hemp fibres was determined for unretted (R0) and retted hemp fibres (R3, R5 and R9). The main components of the hemp fibres are cellulose, hemicelluloses, lignin and pectins. As it can be seen in Fig. 7 the field retting treatment affects biochemical composition of the hemp fibres. A gradual and significant increase of the cellulose fraction from $63 \%$ to $77 \%$ after 9 weeks of the field retting was observed. Pectins are degraded at the early stage $(7.8 \%-4.9 \%)$ and thereafter remained stable. Hemicelluloses are slightly degraded from $14.1 \%$ to $11.6 \%$ after nine week of retting. These variations during retting were found by different authors. Indeed, 


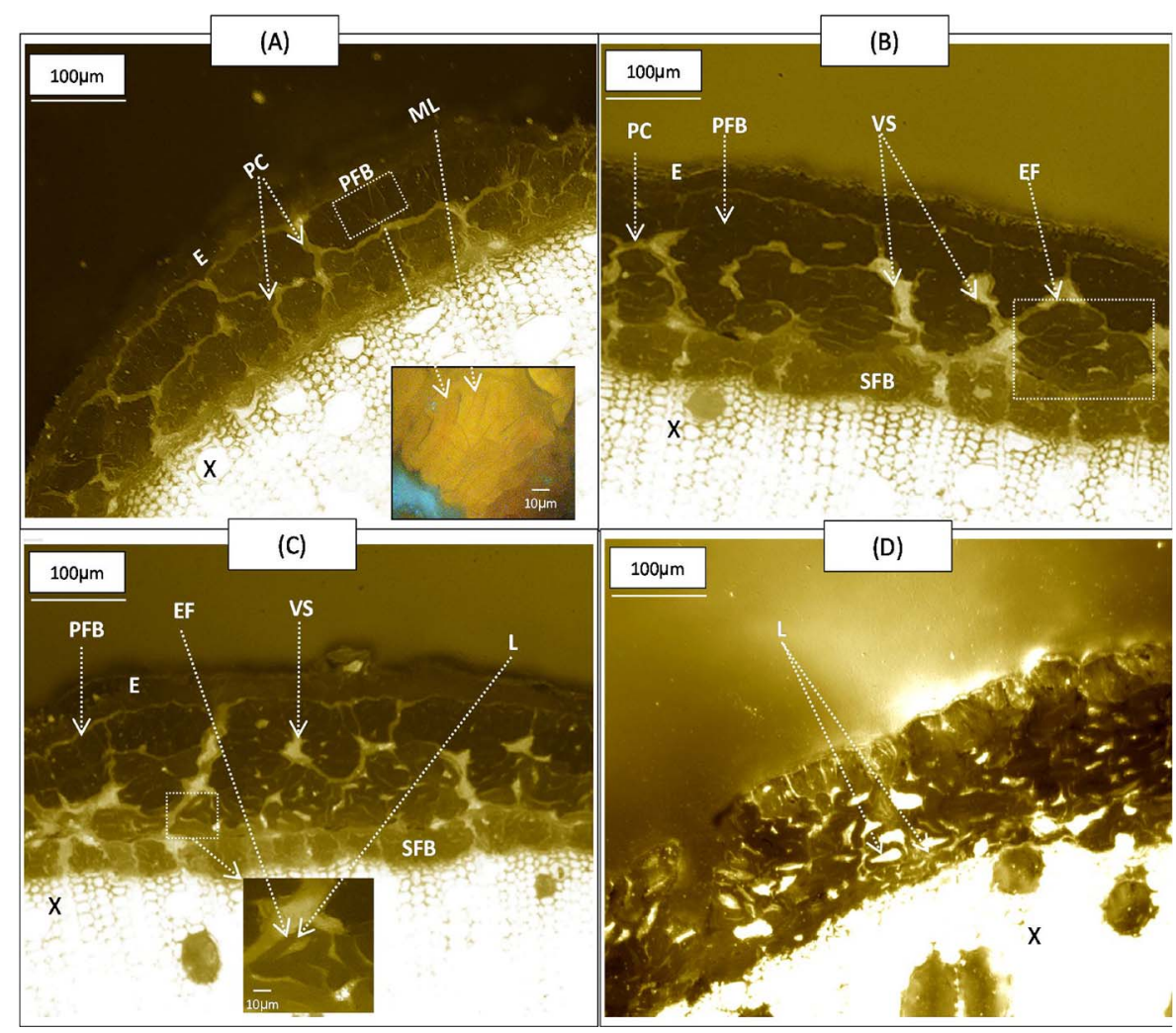

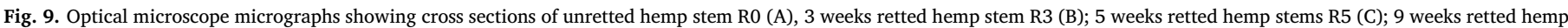

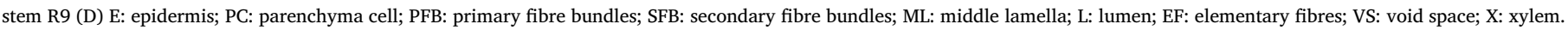

Thygesen et al. (2013) and Nykter et al. (2008) used the same extraction method as those of this study and found similar relative abundances for cellulose, and hemicelluloses for unretted hemp fibres. As concerns Liu et al. (2015a), these authors highlight an increase of cellulose content at early stage of field retting of hemp fibres with a decrease of the pectins and hemicelluloses. Fig. 7 shows also that minerals (ash) and lipophilic extractives were removed during retting. In contrast, the lignin content increases surprisingly during retting. Some authors (Liu et al., 2015a; Placet et al., 2017) assumed that this apparent increase in lignin content is due to a lower degradation of lignin, which becomes concentrated when the other components (lipophilic extract, ash and carbohydrates) are removed at the same time. We have to be aware that the quantification of the mean components is relative and then could explain the increase of lignin quantity with retting. Placet et al. (2017) suggested another assumption in relation with the Klason method used for lignin content determination. Indeed through this method, other phenolic or protein components that evolve during retting are probably also determined. The fibres extraction from the stems may also contribute in increasing of the lignin. The different structures of the stems (e.g. epidermis, xylem) become weaker with retting. Therefore, when bast fibres extracted from the retted stems, micro-residuals xylem (shives) bound to the fibres and could bias the real evolution of lignin during retting.

In addition to biochemical analyses, the cellulose organization of unretted and retted hemp fibres was characterized using X-ray diffraction. Fig. 8A shows X-ray diffractograms of hemp fibres collected at different retting times. The observed major crystalline peaks are located at $2 \theta$ diffraction angles of $14.8^{\circ}, 16.2^{\circ}$ and $22.6^{\circ}$, which correspond to diffraction planes of cellulose type I: (101), (101) and (002) respectively. It can be observed that the intensity of crystalline peaks is significantly increased with increasing of retting duration. In order to quantify these differences, the crystalline order index (CI) was determined as described in $\$ 2.2 .3$ (Fig. 8B).

The X-ray crystalline order index (CI) results are present in Table 2.
CI increased with the field retting duration from $53 \%$ for unretted fibres (R0) to $58 \%, 68 \%$ and $73 \%$ for R3, R5 and R9 retted fibres respectively. This result could be related to the degradation of non-cellulosic compounds during retting as shown previously in biochemical analysis. For unretted hemp fibre, the presence of a great amount of amorphous components such as hemicelluloses, lignin, and pectins between the cellulose micro-fibrils cause disoriented areas, which could undesirably influence the crystallinity of the cellulose micro-fibrils. On the other hand, the removal of amorphous materials during retting treatment leads to a better packing of the cellulose chains. An increase of cellulose fraction and cellulose crystallinity during field retting could impact positively the fibre mechanical properties (Marrot et al., 2013; Placet et al., 2012; Alemdar and Sain, 2008).

The change in biochemical composition and crystallinity of cellulose of the fibres during field retting is most probably related to the microorganisms activities (Ribeiro et al., 2015). Both biofilm growth (ESEM investigations) and metabolic activity of microorganisms would lead to the removal of non-cellulosic materials which indirectly increase the percentage of cellulose in fibres (relative abundances).

\subsection{Influence of field retting duration on the morphology of the hemp fibres}

The optical microscope micrographs of cross-sections of unretted (R0) and retted hemp stem (R3, R5 and R9) is shown in Fig. 9. Images reveal the impact of the field retting duration on the morphology of the hemp fibres. The main parts of the hemp stem are central woody core and surrounding cortex which contains fibres bundle, epidermis, and cortical parenchyma. These two parts are linked by the cambium. Fig. 9A presents a cross section of the unretted hemp stem (R0) where the different parts of the stem are intact and well organized. The hemp fibres are combined in form of bundles as in living plants. In contrast, when the stems are field retted, their structure changed as can be seen in Fig. 9B, C and D. After 3 weeks of retting (Fig. 9B), the parenchyma cells interspersed among bast fibres and fibre bundles started to be 

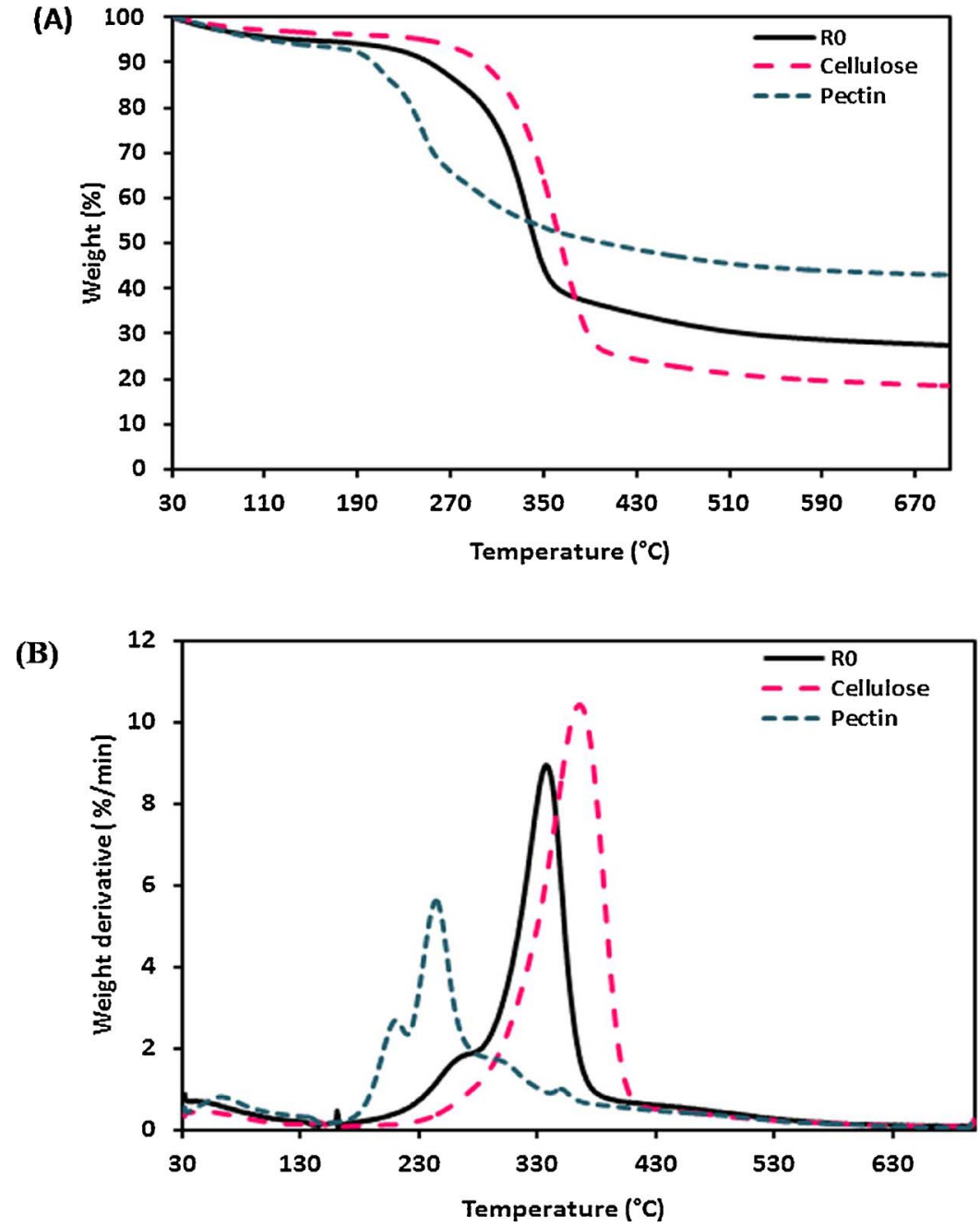

Fig. 10. TGA (A) and DTGA (B) curves of unretted fibres (R0) compared to element constituents (commercial pectin and cellulose).

removed resulting in a few open spaces between fibre bundles. Consequently, the fibre bundles began to be separated as well into smaller fibres bundles. As the field retting progressed, more separation of the fibre bundles into smaller fibre bundles and elementary fibres can be seen for 5 weeks retted hemp stems (R5) (Fig. 9C). In addition, void spaces are evident around the elementary fibres and the lumen of the elementary fibres can be also distinctly observed. For 9 weeks retted stem (R9) (Fig. 9D), the different parts of the stem were affected by the field retting. The epidermis layer and cambium are completely removed, the structure of central woody core is weaker and the bundles of fibres were considerably separated.

These significant changes on the morphology of the hemp fibres during field retting process are due to the action of microorganisms that gradually cover entire of the stems surface (ESEM observations). The microbial activity during field retting would permit the removal of intercellular substance and of material which is in agreement with the biochemical analyses and mainly with pectins and waxes degradation that leads to a separation i) of the bast fibre bundles from the central woody core and epidermis and ii) into smaller bundles and individual fibres. Further investigation into the temporal dynamics of the structure of microbial communities is then required to better understand biological mechanisms occurring during field retting. As expected, this result confirms the positive impact of field retting on the separation of the fibre bundles from the cortex tissues.

\subsection{Influence of field retting duration on thermal stability of the hemp fibres}

The thermal stability of the hemp fibres as a function of retting times was assessed on through TGA experiments. Separate constituents of plant fibres (cellulose and pectins) were first analyzed and compared to unretted hemp fibres (Fig. 10).

Thermographs of pectins and cellulose reveal a major peak at about $240{ }^{\circ} \mathrm{C}$ and $395^{\circ} \mathrm{C}$, respectively. The degradation temperature of cellulose is higher than the pectins due to the crystalline structure of cellulose. The cellulose structure contains strong intramolecular and intermolecular hydrogen bonding that requires high energies to be broken down (Kabir et al., 2013). The unretted fibres mass loss curve highlights three mass losses, the first one at about $30-100{ }^{\circ} \mathrm{C}$ related to moisture removal, the second at about $260^{\circ} \mathrm{C}$ attributed to decomposition of non-cellulosic components (pectins and hemicelluloses) and the third one at about $335^{\circ} \mathrm{C}$ due to cellulose degradation. The peaks are partly superimposed on temperature scale, but can be clearly observed on DTGA curve. Similar range of degradation temperature of hemp fibres constituents was found in several previous studies (Ghetti et al., 1996; Kabir et al., 2013; Ouajai and Shanks, 2005; Placet et al., 2017).

The effect of field retting duration on the hemp fibre thermal stability is presented in Fig. 11. It can be observed that the thermal stability changed during field retting treatment. The increase of retting 

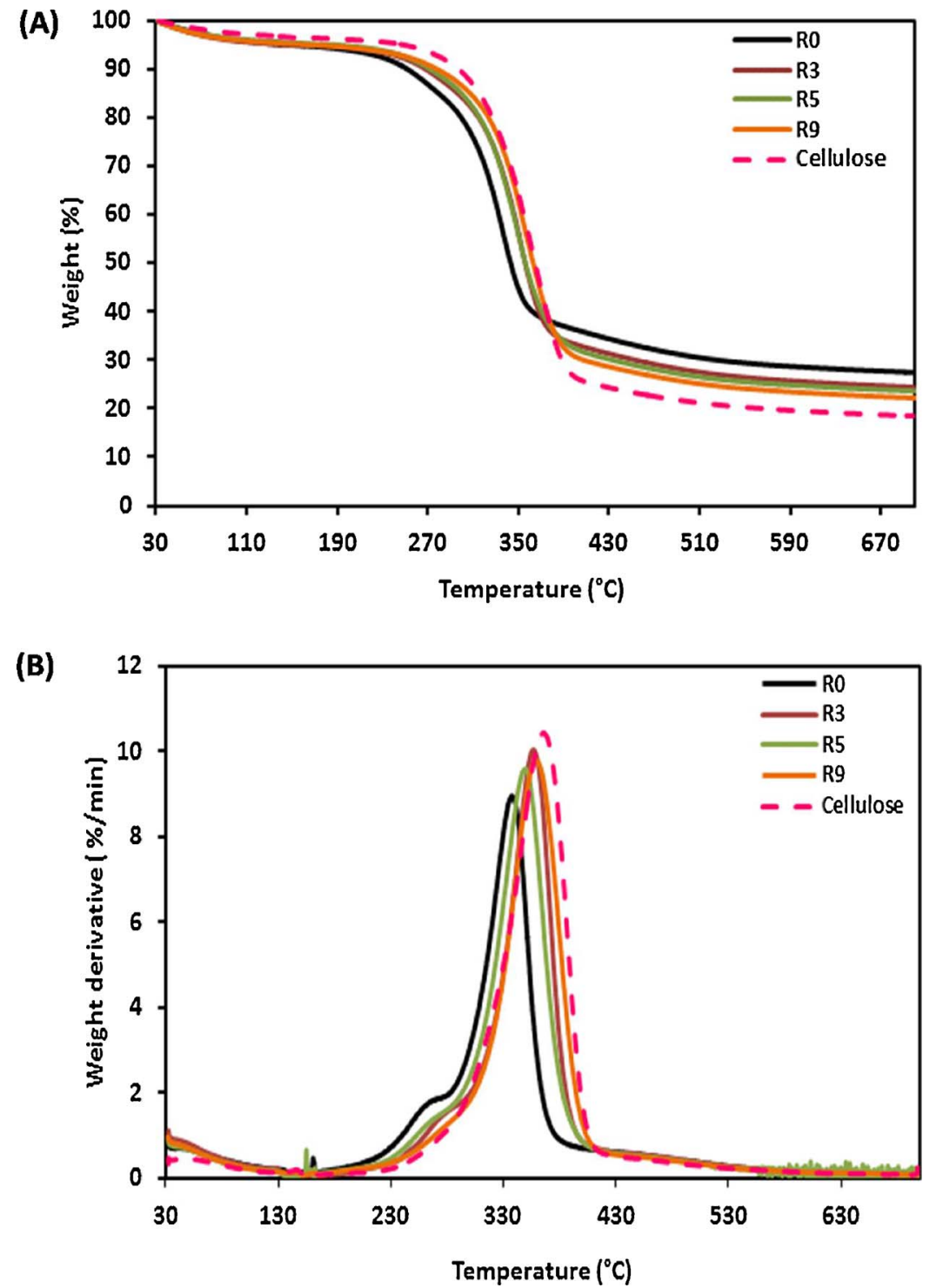

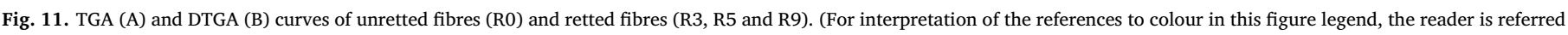
to the web version of this article.)

duration led to a gradual increase of the fibres thermal stability in the $200-400{ }^{\circ} \mathrm{C}$ temperature range corresponding to both pectins and hemicelluloses (shoulder peak) and to cellulose (main peak) decompositions. On one hand it can be observed that the intensity of the pectins and hemicelluloses peak decreases as a function of retting duration (Fig. 11B). This could be explained by the removal of portion of these non-cellulosic components during retting. However, this peak is not clearly visible or disappeared for the high-retted hemp fibres, indicating that non-cellulosic components were quasi totally removed. On the other hand an increase of field retting duration leads to a gradual increase of decomposition temperature of cellulose. It is due to the removal of non-cellulosic components which induces a higher structural order of cellulose that requires a higher degradation temperature. This result is well correlated to biochemical and X-Ray diffraction analyses as shown in Fig. 12. This figure reveals that the degradation temperature of cellulose increases proportionally with the increment of crystallinity and cellulose fraction during retting. This indicates that thermal stability of the fibres can be enhanced with a long field retting duration.
3.5. Influence of field retting duration on the tensile properties of the fibre bundles

Fig. 13 shows the results of the fibre bundle tensile test for unretted (R0) and retted hemp fibres (R3, R5 and R9). Since both failure stress and Young's modulus depend on the fibre diameter (Charlet et al., 2007; Duval et al., 2011; Placet et al., 2012), the average diameter of fibre bundles for each retting time is also reported for comparison. The diameters of fibres selected for tensile test are between 100-230 $\mu \mathrm{m}$ (Fig. 14). The obtained results indicate that the retting duration influences the mechanical properties of hemp fibres. The tensile strength differs significantly ( $p<0.01$ ) between unretted fibres (R0) and retted fibres (R3, R5 and R9), and no significant difference ( $>0.05)$ is noticed between values of the fibres collected at different retting times (R3, R5 and R9). Indeed, the tensile strength of fibres increases gradually from $174 \mathrm{MPa}$ for unretted fibres to $342 \mathrm{MPa}$ for 5-weeks retted fibres, and then decrease slightly to $324 \mathrm{MPa}$ after a prolonged field retting of 9 weeks (median values) (Fig. 13A). The Young's modulus of retted fibres (R3, R5 and R9) increases significantly ( $p<0.05)$ to 


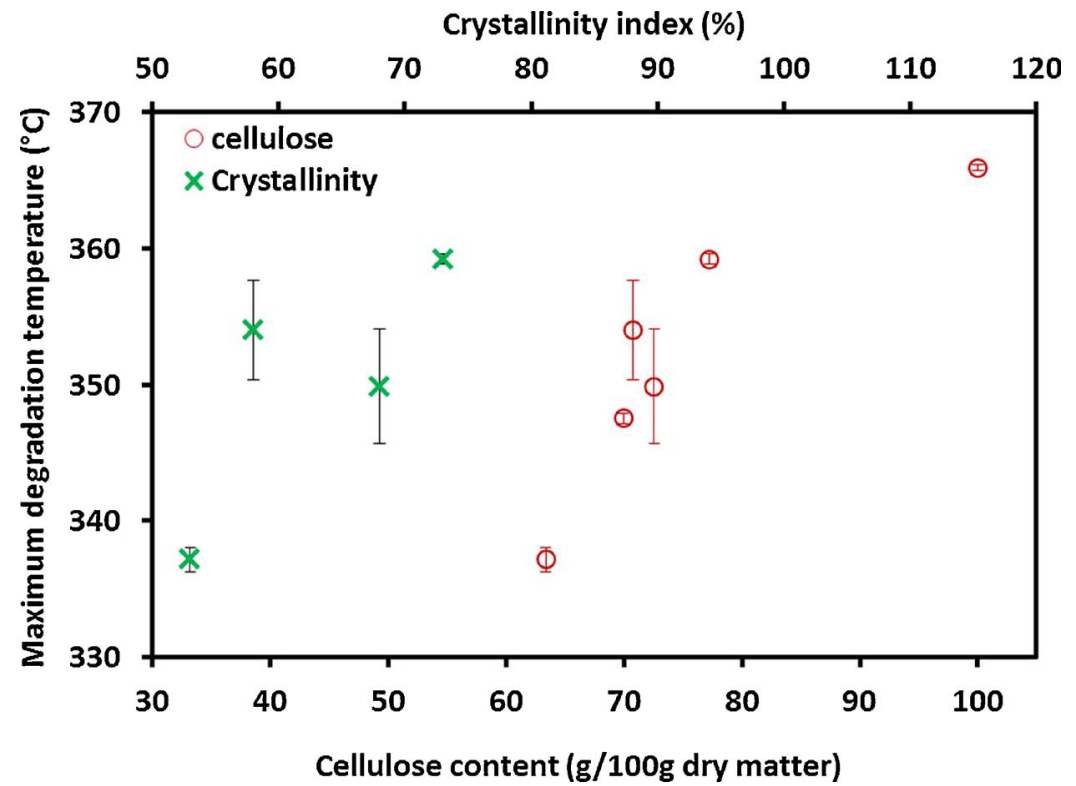

Fig. 12. Correlation between degradation temperature of cellulose (TGA), cellulose fraction (biochemical analysis) and cellulose crystallinity (DRX experiments).
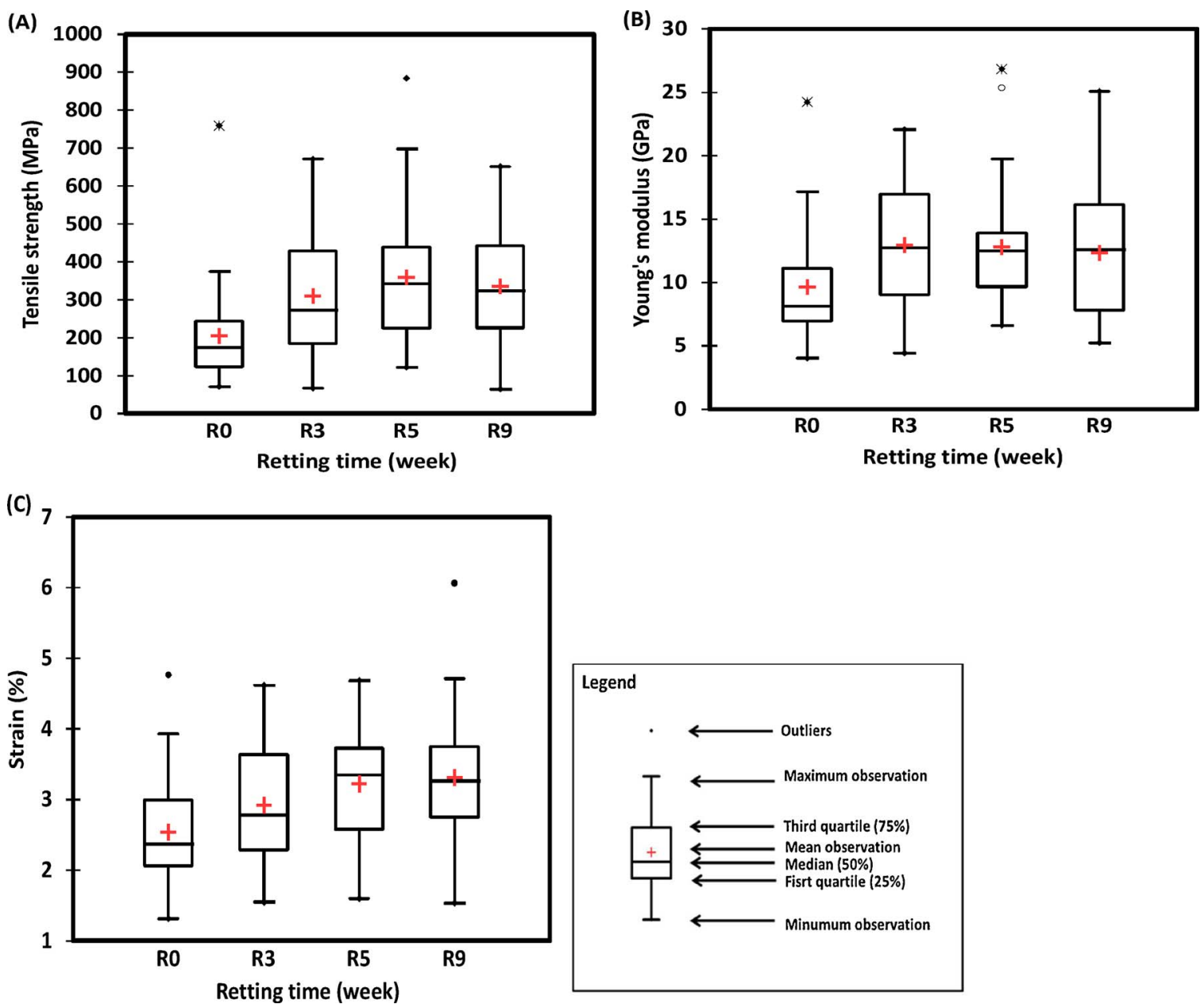

Fig. 13. Box plots of tensile strength (A), Young's modulus (B), and ultimate strain (C) of unretted and retted fibres (R3, R5 and R9).

12 GPa compared to that of unretted fibres (8 GPa) (Fig. 13B), however, no significant difference is observed $(\mathrm{p}>0.05)$ between the Young's modulus of the fibres collected at different retting times (R3, R5 and R9). The strain at failure increases significantly $(\mathrm{p}<0.01)$ from $2.4 \%$ for unretted fibres (R0) to $2.8 \%, 3.4 \%, 3.3 \%$ (median values), for retted hemp fibres R3, R5 and R9, respectively (Fig. 13C).

The change in tensile properties during field retting treatment can be explained by the results described in previous sections. A noticeable 


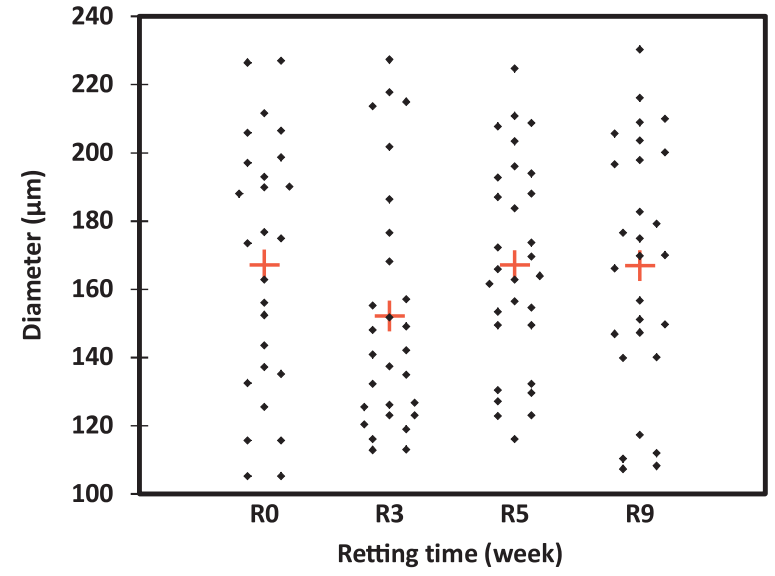

Fig. 14. Scattergrams of measured diameters of unretted (R0) and retted fibres (R3, R5 and R9). The red crosses correspond to the means.

increase in both cellulose crystallinity and cellulose fraction during field retting could cause an increase of mechanical properties. This result is not surprising as it has been reported that both crystallinity and higher fraction of cellulose bring a better tensile performance (Alemdar and Sain, 2008; Marrot et al., 2013; Placet et al., 2012; Reddy and Yang, 2005).

Furthermore, the lower mechanical properties of unretted hemp fibres could be due to the presence of weak areas and a large amount of non-cellulosic substances such as pectins and hemicelluloses. This induces interfacial decohesion within fibres bundle. Another explication could be related to the manual extraction of the fibres that is not an easy step because of the presence of the cementing compounds (e.g. pectins) that bind the different parts of the stem. Therefore, hand extraction of fibres after removing epidermis using razor blade, may cause some micro-defects in the unretted hemp fibres. In contrast, when the stems are retted, as the cementing compounds are degraded, the generation of micro-defects in the fibres is limited and the manual fibres extraction is easier.

Mechanical properties of the fibres are governed by the retting duration which depends also on the weather conditions. In the present work, the field retting treatment of fibres harvested at the beginning of flowering was performed under summer weather conditions in the south of France. Therefore, in these conditions, results reveal that a long period of retting ( 5 weeks) is required for obtaining the highest mechanical properties. In contrast, Liu et al. (2015a) show that mechanical properties increase at the early stage of retting when the field retting period is carried out under a colder and homogeneous rainy weather condition, and then decrease rapidly due to the accelerated degradation of cellulose by microorganisms. Placet et al. (2017) as well observed that a prolonged field retting until 5 weeks under rainy weather may lead to over-retted fibres. Hence, an extended of field retting duration under wet weather conditions must be avoided.

\section{Conclusion}

In this study, the influence of field retting duration on biochemical, microstructural, thermal and mechanical properties of hemp fibres harvested at the beginning of flowering was investigated. The retting period of fibres occurs under summer weather conditions.

A color change of fibres from light green (R0) to grey (R9) was observed either on stems or on fibre bundles extracted from stems. A colonization of microorganisms on stems surface has been highlighted from 3-weeks retting fibres by using ESEM. Removal of the cortical parenchyma, pectic middle lamella and other cementing compounds was given in evidence by both optical microscope (qualitative analysis) and biochemical measurements (quantitative analysis). The cellulose fraction increase (from $63 \%$ for R0 to $77 \%$ for R9) with a decrease of non-cellulosic component (from $7.81 \%$ to $4.19 \%$ for pectins for example) during retting. The increase of cellulose organization from $53 \%$ for R0 to $73 \%$ for R9 was characterized using X-ray diffraction. This increase of cellulose organization is related to degradation of non-cellulosic components during retting. TGA measurements, showed a gradual increase in thermal stability of fibres during field retting and a lower mass loss related to non-cellulosic components decomposition in relation with the removal of these constituents along retting. The tensile properties of fibre bundles increase during retting due to the increase of both cellulose crystallinity and the cellulose fraction.

All these results highlight that field retting can induce a significant change on hemp fibres properties, as well mechanical and thermal properties than fibre microstructure and microbiological medium. A 5 weeks field retting duration should be the best duration for higher mechanical properties of hemp fibres when harvested at beginning of flowering and retted in summer weather conditions. This approach also highlights that weather conditions are crucial for the implementation of the field retting process.

Further investigations will concern the evaluation of the field retting effect when fibres are harvested at different growth stages (beginning of flowering, end of flowering, and seed maturity) and with different weather conditions. In addition, the characterization of the structure of microbial communities should provide deep insights for understanding of biological mechanisms during retting. These future results should greatly determine easy and common indicators for improving the control of field retting process.

\section{Funding}

This research did not receive any specific grant from funding agencies in the public, commercial, or not profit sector.

\section{Acknowledgements}

The authors would like to acknowledge the "CIVAM Chanvre Gardois association (Bouquet, France)" for making available for us a plot of land to conduct this study. The authors wish also to express sincere appreciation to Prof. Jean-Louis Fanlo, Dr. Mathilde Chaignaud, Dr. Stephane Cariou, and Dr. Sandrine Bayle for their assistance in this work.

\section{References}

Akin, D.E., Epps, H.H., Archibald, D.D., Sharma, H.S.S., 2000. Color measurement of flax retted by various means. Text. Res. J. 70, 852-858.

Akin, D.E., Condon, B., Sohn, M., Foulk, J.A., Dodd, R.B., Rigsby, L.L., 2007. Optimization for enzyme-retting of flax with pectate lyase. Ind. Crops Prod. 25, 136-146.

Alemdar, A., Sain, M., 2008. Biocomposites from wheat straw nanofibers morphology, thermal and mechanical properties. Compos. Sci. Technol. 68, 557-565.

Aziz, S.H., Ansell, M.P., 2004. The effect of alkalization and fibre alignment on the mechanical and thermal properties of kenaf and hemp bast fibre composites: part 1-polyester resin matrix. Compos. Sci. Technol. 64, 1219-1230.

Blumenkrantz, N., Asboe-Hansen, G., 1973. New method for quantitative determination of uronic acids. Anal. Biochem. 54, 484-489.

Bourmaud, A., Baley, C., 2010. Effects of thermo mechanical processing on the mechanical properties of biocomposite flax fibers evaluated by nanoindentation. Polym. Degrad. Stab. 95, 1488-1494.

Chabbert, B.R.C., Monties, B., Crônier, D., 2005. Structure and chemical composition of bast fibers isolated from developing hemp stem. J. Agric. Food Chem. 53, 8279-8289.

Charlet, K., Baley, C., Morvan, C., Jernot, J.P., Gomina, M., Bréard, J., 2007. Characteristics of Hermès flax fibres as a function of their location in the stem and properties of the derived unidirectional composites. Compos. Part A Appl. Sci. Manuf. 38, 1912-1921.

Dittenber, D.B., Gangarao, H.V.S., 2012. Composites: part A Critical review of recent publications on use of natural composites in infrastructure. Compos. Part A 43, 1419-1429.

Duval, A., Bourmaud, A., Augier, L., Baley, C., 2011. Influence of the sampling area of the stem on the mechanical properties of hemp fibers. Mater. Lett. 65, 797-800.

Fila, G., Manici, L., Caputo, F., 2001. In vitro evaluation of dew retting of flax by fungi from Southern Europe. Ann. Appl. Biol. 138, 343-351.

Ghetti, P., Ricca, L., Angelini, L., 1996. Thermal analysis of biomass and corresponding 
pyrolysis products. Fuel 75, 565-573.

Henriksson, G., Akin, D.E., Hanlin, R.T., Rodriguez, C., Archibald, D.D., Rigsby, L.L., Eriksson, K.L., Russell, R.B., Carolina, S., 1997. Identification and retting efficiencies of fungi isolated from dew-retted flax in the united states and europe. Am. Chem. Soc. 63, 3950-3956.

Joshi, S.V., Drzal, L.T., Mohanty, A.K., Arora, S., 2004. Are natural fiber composites environmentally superior to glass fiber reinforced composites? Compos. Part A Appl. Sci. Manuf. 35, 371-376.

Kabir, M.M., Wang, H., Lau, K.T., Cardona, F., 2013. Effects of chemical treatments on hemp fibre structure. Appl. Surf. Sci. 276, 13-23.

Li, Y., Pickering, K.L., Farrell, R.L., 2009. Determination of interfacial shear strength of white rot fungi treated hemp fibre reinforced polypropylene. Compos. Sci. Technol. $69,1165-1171$.

Liu, M., Fernando, D., Daniel, G., Madsen, B., Meyer, A.S., Ale, M.T., Thygesen, A., 2015a. Effect of harvest time and field retting duration on the chemical composition: morphology and mechanical properties of hemp fibers. Ind. Crops Prod. 69, 29-39.

Liu, M., Fernando, D., Meyer, A.S., Madsen, B., Daniel, G., Thygesen, A., 2015b. Characterization and biological depectinization of hemp fibers originating from different stem sections. Ind. Crops. Prod. 76, 880-891.

Marrot, L., Lefeuvre, A., Pontoire, B., Bourmaud, A., Baley, C., 2013. Analysis of the hemp fiber mechanical properties and their scattering (Fedora 17). Ind. Crops Prod. 51, 317-327.

Martin, N., Mouret, N., Davies, P., Baley, C., 2013. Influence of the degree of retting of flax fibers on the tensile properties of single fibers and short fiber/polypropylene composites. Ind. Crops Prod. 49, 755-767.

Mediavilla, V., Jonquera, M., Schmid-slembrouck, I., 1998. Decimal code for growth stages of hemp (Cannabis sativa L.). J. Int Hemp Ass. 5 (2), 68-74.

Nykter, M., Kyma, H., Belinda, A., Lilholt, H., Thygesen, A., 2008. Effects of thermal and enzymatic treatments and harvesting time on the microbial quality and chemical composition of fibre hemp (Cannabis sativa L.). Biomass Bioenergy 32 (5), 392-399.

Obendorf, S.K., Kyung, H.S., 2006. Chemical and biological retting of kenaf fibers. Text. Res. J. 76, 751-756.

Ouajai, S., Shanks, R.A., 2005. Composition, structure and thermal degradation of hemp cellulose after chemical treatments. Polym. Degrad. Stab. 89, 327-335.

Pallesen, B.E., 1996. The quality of combine-harvested fibre flax for industrials purposes depends on the degree of retting. Ind. Crops Prod. 5, 65-78.

Placet, V., Trivaudey, F., Cisse, O., Gucheret-Retel, V., Boubakar, M.L., 2012. Diameter dependence of the apparent tensile modulus of hemp fibres: a morphological, structural or ultrastructural effect? Compos. Part A Appl. Sci. Manuf. 43, 275-287.

Placet, V., Day, A., Beaugrand, J., 2017. The influence of unintended field retting on the physicochemical and mechanical properties of industrial hemp bast fibres. J. Mater. Sci. 52, 5759-5777.

Reddy, N., Yang, Y., 2005. Structure and properties of high quality natural cellulose fibers from cornstalks. Polymer 46, 5494-5500.

Ribeiro, A., Pochart, P., Day, A., Mennuni, S., Bono, P., Baret, J.-L., Spadoni, J.-L. Mangin, I., 2015. Microbial diversity observed during hemp retting. Appl. Microbiol. Biotechnol. 4471-4484.

Schäfer, T., Honermeier, B., 2006. Effect of sowing date and plant density on the cell morphology of hemp (Cannabis sativa L.). Ind. Crops Prod. 23, 88-98.

Sharma, H., Brown, B.Y.A.E., 1984. Production of polysaccharide-degrading enzymes by saprophytic fungi from glyphosate-treated flax and their involvement in retting. Ann. Appl. Biol. 105, 65-74.

Sisti, L., Totaro, G., Vannini, M., Fabbri, P., Kalia, S., Zatta, A., Celli, A., 2016. Evaluation of the retting process as a pre-treatement of vegetable fibers for the preparation of high-performance polymer biocomposites. Ind. Crops Prod. 81, 56-65.

Stamboulis, A., Baillie, C.A., Peijs, T., 2001. Effects of environmental conditions on mechanical and physical proprties of flax fibers. Compos. Part A 32, 1105-1115.

Tahir, P.M., Ahmed, A.B., SaifulAzry, S.O.A., Ahmed, Z., 2011. Retting process of some bast plant fibers and its effect on fibre quality: a review. Bioresources 6 (4), 5260-5281.

Thygesen, A., Liu, M., Meyer, A.S., Daniel, G., 2013. Hemp fibres: enzymatic effect of microbial processing on fibre bundle structure. In: Risoe International Symposium on Materials Scienc Proceedings, 2013e. Proceedings, 2013. Forskningscenter Risoe Materialeforskning. pp. 373-380.

Vignon, M.R., Dupeyre, D., Garcia-Jaldon, C., 1997. Morphological characterization of steam-exploded hemp fibers and their utilization in polypropylene-based composites. Bioresour. Technol. 58, 203-215.

Wambua, P., Ivens, J., Verpoest, I., 2003. Natural fibres: can they replace glass in fibre reinforced plastics? Compos. Sci. Technol. 63, 1259-1264. 